\title{
Considering Drug-Associated Contexts in Substance Use Disorders and Treatment Development
}

\author{
Mandy Rita LeCocq ${ }^{1} \cdot$ Patrick A. Randall ${ }^{2}$ - Joyce Besheer ${ }^{3} \cdot$ Nadia Chaudhri $^{1}$ (D)
}

Published online: 2 January 2020

(C) The American Society for Experimental NeuroTherapeutics, Inc. 2020

\begin{abstract}
Environmental contexts that are reliably associated with the use of pharmacologically active substances are hypothesized to contribute to substance use disorders. In this review, we provide an updated summary of parallel preclinical and human studies that support this hypothesis. Research conducted in rats shows that environmental contexts that are reliably paired with drug use can renew extinguished drug-seeking behavior and amplify responding elicited by discrete, drug-predictive cues. Akin to drugassociated contexts, interoceptive drug stimuli produced by the psychopharmacological effects of drugs can also influence learning and memory processes that play a role in substance use disorders. Findings from human laboratory studies show that drug-associated contexts, including social stimuli, can have profound effects on cue reactivity, drug use, and drug-related cognitive expectancies. This translationally relevant research supports the idea that treatments for substance use disorders could be improved by considering drug-associated contexts as a factor in treatment interventions. We conclude this review with ideas for how to integrate drug-associated contexts into treatment-oriented research based on 4 approaches: pharmacology, brain stimulation, mindfulness-based relapse prevention, and cognitive behavioral group therapy. Throughout, we focus on alcoholand tobacco-related research, which are two of the most prevalent and commonly misused drugs worldwide for which there are known treatments.
\end{abstract}

Keywords Alcohol $\cdot$ Tobacco $\cdot$ Cue $\cdot$ Treatment $\cdot$ Relapse

\section{Overview}

A unifying theory in research on substance use disorders is that environmental stimuli that are associated with drug use influence motivational processes that contribute to ongoing drug use and facilitate relapse [1-3]. These environmental stimuli include cues that reliably occur in close temporal proximity with drug use, called "proximal drug cues" in human studies and "discrete drug cues" in animal models. They also

Nadia Chaudhri

nadia.chaudhri@concordia.ca

1 Department of Psychology, Center for Studies in Behavioural Neurobiology, Concordia University, 7141 Sherbrooke Street West, Room SP 244, Montreal, Quebec H4B-1R6, Canada

2 Department of Anesthesiology and Perioperative Medicine, Penn State College of Medicine, Hershey, Pennsylvania, USA

3 Department of Psychiatry, Bowles Center for Alcohol Studies, School of Medicine, University of North Carolina at Chapel Hill, Chapel Hill, North Carolina, USA include the contexts that are routinely associated with drug use, where a context could be a physical space, social setting, or drug-induced, interoceptive state.

The notion that drug-associated contexts play a role in substance use disorders has imbued the scientific literature for decades. For example, in a study from 1986, participants were asked to identify "bells which trigger a craving for alcohol" [4]. Responses varied, but included being at bars or in social situations. Pioneering studies on the role of context in substance use disorders focused on 2 paradigms - conditioned tolerance [5-7] and conditioned place preference/aversion [8-10]. Conditioned tolerance is the observation of tolerance to a drug's pharmacological effects following repeated administration in a specific context, coupled with the attenuation of tolerance when the same drug dose is administered in a different context [5, $11,12]$. Place conditioning refers to the development of a conditioned preference for or aversion of physical contexts associated with drugs [8-10]. Both paradigms have yielded important insights about processes that regulate context conditioning with experimenter-administered drugs. 
Drug-associated contexts can also have a marked effect on instrumental and Pavlovian-conditioned responding associated with voluntary drug intake, as well as on learning and memory processes that contribute to substance use disorders. Specifically, studies in rats show that physical contexts associated with prior drug use can renew extinguished instrumental and Pavlovian-conditioned responses associated with prior drug availability. Drug-associated contexts can also amplify non- or partially extinguished responses elicited by Pavlovian, drug-predictive cues. Furthermore, drug interoceptive stimuli produced by the psychopharmacological effects of drugs can serve as discriminative stimuli for reward-seeking behavior and can set the occasion for learning cue-reward associations. In people, drug-associated contexts can evoke conditioned reactivity, amplify reactivity to proximal drug cues, increase actual drug intake, and affect drug-related cognitive expectancies. Here, we review this research in an effort to highlight recent translationally relevant findings that have been obtained across species.

Given the vast and global socioeconomic and health implications of substance use disorders, there has been a tremendous effort aimed at treatment development, and researchers have proposed that knowledge about how contexts can influence learned behavior could be harnessed to improve treatment efficacy [13-15]. Since then, pharmacological research has yielded effective medicines to treat alcohol use disorders and tobacco use; fundamental neuroscience research has prompted the revolutionary exploration of brain stimulation techniques to promote abstinence; and decades of psychobehavioral research has matured into approaches that empower treatment-seekers with cognitive and behavioral skills to combat relapse. In this review, we conclude by presenting ideas for how these specific treatment approaches might be enhanced by considering drug-associated contexts in treatment development.

\section{Definitions and Scope}

In accordance with human studies, we operationally define sensory stimuli that reliably accompany drug use (e.g., the taste or smell of alcohol, the sight of a lit cigarette in an ashtray) as proximal drug cues in human studies [16, 17]. Animal models mimic proximal drug cues by pairing drug delivery with a brief, nondrug stimulus like the onset of a light, tone, or both stimuli combined [18-20]. We define these stimuli as discrete drug cues.

The word "context" can encompass a vast array of external and internal stimuli. In this review, we focus on studies that examined the effects of drug-associated contexts on instrumental drug-seeking behavior, reactivity to discrete/ proximal drug cues, drug use, and drug-related cognitions. A drug-associated context is defined as a stable configuration of multimodal stimuli that is consistently present in the background during drug use, and is thus likely to have gained associative value through repeated pairings with drug use [21].

Drug use in humans is often a social process, and it can be challenging to disentangle drug-associated contexts from social stimuli (i.e., other people) that are reliably present in those contexts. Therefore, we also briefly describe research on the effects of social stimuli on drug use and drug-related cognitions.

The psychopharmacological effects of drugs can produce drug interoceptive stimuli (i.e., internal drug states) that serve as discriminative cues that signal when a behavior might result in drug delivery $[22,23]$. Because this function of drug interoceptive stimuli can parallel some effects of drug-associated contexts, we briefly review studies that examined the contribution of drug interoceptive stimuli to learning processes that are implicated in substance use disorders.

Given the extensive evidence that drug-associated contexts can influence multiple facets of behavior related to drug use, we support the position raised by others [13-15] that drugassociated contexts should be integrated into treatmentoriented research. We conclude with new ideas for how to do this in four promising areas of treatment research, namely pharmacology, brain stimulation, mindfulness-based relapse prevention, and cognitive behavioral group therapy. The scope of this review is restricted to studies conducted using alcohol and tobacco/nicotine, as these are globally the most frequently used drugs [24], for which known treatments exist [25-27].

\section{Context-Induced Renewal of Drug-Seeking Behavior}

\section{Animal Models}

The renewal paradigm [28] is one of the primary behavioral animal models used to investigate the influence of drugassociated contexts in relapse. In the first published report, rats were trained to press an "active" lever for intravenous infusions of a heroin-cocaine ("speedball") mixture in a distinctive environmental context called "context A" [29]. Each drug infusion was paired with a brief, white cue-light to signal drug delivery, and presses on a second "inactive" lever were recorded but not reinforced. Following stable self-administration, extinction was conducted in a second, different context ("context B"), in which active lever-pressing decreased as a result of being reinforced by the cue-light alone (i.e., speedball was withheld). At test, a return to context A stimulated a renewal of active lever-pressing (ABA renewal), relative to controls that received self-administration training, extinction, and test in the same context (AAA control), or self- 
administration training in one context and extinction and test in a second, different context (ABB control). At test, active lever presses resulted in presentations of the cue-light but no speedball, and the renewal effect was specific to the active lever. This finding of ABA renewal of instrumental, drugseeking behavior supports the hypothesis that contexts associated with prior drug use can precipitate a "relapse-like" return of extinguished, drug-seeking behavior.

ABA renewal of drug-seeking behavior is a ubiquitous effect. Contexts associated with various intravenously selfadministered substances, including heroin [30, 31], cocaine [29, 32-35], oxycodone [36], and nicotine [37-39], prompt renewal after extinction in a different context. There is also ample evidence of ABA renewal of instrumental responding associated with prior receipt of orally consumed reinforcers, like alcohol [40-44], sucrose [41, 45, 46], or food pellets [47, 48]. Studies in the latter domain found that entries into the magazine where reinforcer delivery occurred during selfadministration also underwent ABA renewal [44, 49]. Through an innovative twist of the model, ABA renewal was also observed when in place of extinction, instrumental responding was reduced by sporadically pairing active lever presses with a mild foot shock in context $\mathrm{B}[50,51]$. Thus, the ABA renewal model can capture the influence of drugassociated contexts on drug-seeking behavior that was reduced either through the omission of drug delivery (extinction) or the introduction of a response-contingent, negative consequence (punishment).

$\mathrm{ABA}$ renewal is produced by a return to the conditioning context following extinction in a different context. However, renewal can also be triggered by removal from a context with a mixed history of reinforcement and extinction (AAB renewal) and by removal from a context associated with extinction and placement into a new context (ABC renewal). Although $\mathrm{ABA}$ renewal of instrumental drug-seeking behavior is robust and reliable, $\mathrm{AAB}$ and $\mathrm{ABC}$ renewal are less frequently tested and produce more nuanced effects. For example, one study showed that $\mathrm{AAB}$ and $\mathrm{ABC}$ renewal of instrumental responding on a food-associated lever were numerically weaker effects than ABA renewal [47]. Another study reported ABC renewal of instrumental responding associated with prior sucrose delivery, but did not observe $\mathrm{ABC}$ renewal of instrumental responding associated with prior alcohol delivery [41]. Finally, the first study to report ABA renewal of instrumental, speedballseeking did not find evidence of AAB renewal [29]. Thus, although a return to the self-administration context is a strong trigger for renewal, removal from the extinction context and placement into a new context ( $\mathrm{ABC}$ renewal) and removal from a context with a mixed history of self-administration and extinction (AAB renewal) are not as effective.

Renewal has also been investigated using appetitive Pavlovian conditioning procedures. Although it takes longer in the absence of food or fluid restriction [52], animals can learn to associate a conditioned stimulus (CS) with an appetitive unconditioned stimulus (US). Unsurprisingly, ABA renewal is a robust phenomenon in appetitive Pavlovian conditioning tasks in which a CS predicts food pellets [53], sucrose [44], or alcohol [44, 54, 55]. However, results from studies using other renewal designs are, once again, equivocal. One study reported $\mathrm{AAB}$ renewal of responding to a $\mathrm{CS}$ associated with food pellets [56], but unpublished data from our laboratory failed to observe $\mathrm{AAB}$ or $\mathrm{ABC}$ renewal of responding to a CS associated with either sucrose or alcohol, despite robust ABA renewal (Khoo, Sciascia, Brown, and Chaudhri, unpublished). Thus, in both instrumental and Pavlovian models, a return to the drug-associated conditioning context appears to be the most prominent trigger for renewal.

\section{Human Studies}

Effects akin to renewal have been reported in human participants. In one study [57], daily cigarette smokers were presented with an ashtray and given the opportunity to smoke in a room with specific decor. Participants then underwent extinction in a different room where the ashtray was present, but smoking was not permitted. Subsequently, participants who were returned to the original room (ABA renewal) reported a greater urge to smoke in the presence of the ashtray, compared with participants who were tested in the extinctionassociated room (ABB control). In another study conducted in casual alcohol drinkers, conditioned responding elicited by the smell of beer was measured in a specific room. Participants were then either returned to this room or brought into a second, different room, where they repeatedly sniffed the beer until their self-reported urge to drink ratings returned to baseline (i.e., extinction). All participants were then instructed to smell the beer in the initial room. Those participants who had received extinction in the second room (ABA renewal) reported greater urge to drink and had increased salivation, compared with participants who had received extinction and test in the same room (AAA control) [58]. Thus, contexts have the capacity to renew conditioned cue reactivity in people.

\section{Context Impacts Cue Reactivity, Drug Use, and Drug-Outcome Expectancies}

\section{Animal Models}

In the renewal model, drug-related responding is systematically extinguished before the test. However, this type of rigorous extinction in people with substance use disorders is infrequent. Interestingly, contexts associated with prior drug intake can also elevate responding elicited by non- or partially extinguished discrete, drug-predictive cues. One model to describe this finding used rats that were trained in a specific 
context to associate a brief, auditory CS with alcohol that was delivered into a fluid port for oral intake. On alternating days, rats were exposed to the same chambers that were set up as a different context, where alcohol was never delivered. After an equal number of sessions in both contexts, CS-elicited fluid port entries were tested in both contexts using a counterbalanced, within-subject design. At test, the CS was presented as during Pavlovian conditioning, but no alcohol was delivered. Results showed that CS-elicited port entries were significantly higher at test in the context associated with prior receipt of alcohol, compared to the second context that was equally familiar, but motivationally neutral [18, 59, 60]. Importantly, CS-elicited port entries in the familiar, neutral context did not differ from CS-elicited port entries in a novel context, supporting the idea that the familiar context was neutral and not inhibitory $[59,61]$. In a similar task, context was also found to signal the temporal relation between CS onset and US delivery (Valyear and Chaudhri, unpublished). Thus, context can control the magnitude of responding to a nonextinguished CS, as well as provide more nuanced information about the temporal relation between cues and alcohol delivery.

\section{Human Studies}

Ecological momentary analysis is being used to describe how drug use occurs in real-world, drug contexts. This technique uses self-report, geolocation, photographs, and videos to sample behaviors in their natural environments [62, 63]. It produces real-time measures of physical locations, social settings, and amounts of drug consumed, while minimizing recall biases. Studies using ecological momentary analysis suggest that drinking and smoking behaviors are influenced by drugassociated contexts, which are often imbued with social stimuli. For example, most drinking episodes occur in bars, in an individual's home, or at other people's homes [64, 65]. Drinking episodes are also more likely to occur when other people are drinking [65]; one study reported that other people were drinking in 56\% of drinking episodes [64]. Smoking is more likely to occur in a car, at work, at home, and at a bar [66-68]. Interestingly, smoking is reported more frequently while in the company of friends, other smokers, and while consuming coffee or alcohol [66-68]. These data provide valuable qualitative information about the relation between context and drug use.

In research that seeks to empirically manipulate context, one approach is to present participants with pictures of drugassociated contexts. In one series of studies that used this approach, exposure to pictures of smoking contexts that were devoid of proximal smoking cues evoked higher levels of craving to smoke than pictures of neutral stimuli [17]. Interestingly, pictures of personalized smoking contexts evoked stronger reactivity than generic smoking contexts
[69]. Exposure to pictures of proximal smoking cues that were juxtaposed against projected images of smoking contexts also produced more craving than either cue type alone and led to the most rapid onset of cigarette smoking [70]. Finally, exposure to smoking-related contexts decreased the ability of participants to resist smoking, and greater craving was correlated with faster initiation of smoking [71]. Thus, pictures of smoking-associated contexts evoke reactivity, augment reactivity to nonextinguished, proximal smoking cues, and accelerate smoking behavior.

Simulated or imagined drug-associated contexts also impact drug intake. For example, casual drinkers consumed significantly more alcohol in an alcohol taste test task that was conducted in a simulated bar, compared to a laboratory environment [72]. An increase in alcohol intake also occurred when scripts and guided imagery were used to evoke cognitive representations of recent situations that included alcoholrelated stimuli and alcohol consumption [73]. The impact of context on drinking can therefore generalize to cognitive representations of drug-associated contexts.

Drug-associated contexts can also alter alcohol-outcome expectancies - a cognitive measure describing beliefs about the consequences of drinking alcohol [74, 75]. For example, participants reported greater positive outcomes, such as stimulation, perceived self-dominance, and pleasurable disinhibition when queried in a campus bar, compared to a laboratory [76]. The inverse occurred for negative outcomes, such that expectations of cognitive and behavioral impairments and negative self-perception were reported less when participants were in the bar environment [77]. Other alcohol-outcome expectancies, such as positive social interactions, fun, and tension reduction, were also reported as being higher in a bar environment, relative to a context that was not explicitly associated with alcohol [78].

As suggested by ecological momentary analysis, drugassociated contexts are often imbued with social stimuli (i.e., other people), making it relevant to ask if social stimuli impact cue reactivity and drug use. Interestingly, people can function as smoking-associated cues that elicit conditioned responses [79-81]. Daily smokers smoked more cigarettes, and at a quicker rate, in the presence of a confederate who was actively smoking, versus a nonsmoking confederate or social isolation [82-84]. Conversely, the presence of a nonsmoking confederate reduced the number of cigarettes smoked [79, 85], suggesting that people who are not associated with smoking may be a protective factor for abstinence.

Social setting can also alter alcohol-drinking patterns in the laboratory, often without participant awareness. For example, casual alcohol drinkers were more likely to choose an alcoholic beverage over a placebo beverage, despite being unaware of the contents of either beverage, when tested in a social setting compared to social isolation [86]. This effect was replicated in heavy social drinkers, who drank more 
alcohol and at a faster rate in the presence of an alcoholdrinking partner, compared to social isolation [87]. Despite not knowing the contents of a confederate's beverage, participants drank significantly more alcohol when a confederate drank alcohol, compared to when a confederate drank soda [88]. When in the presence of other people, participants also consumed more of what they believed was alcohol, but was actually a placebo, while in a pub environment compared to a library [89].

Finally, social settings can alter psychological responses to alcohol. When in a social setting that included other people also consuming alcohol, participants reported elevated mood, enjoying alcohol more, feeling more intoxicated, and feeling more stimulated $[86,90]$. As well, participants rated risky choices as significantly more attractive after consuming alcohol when isolated, but not when in a group setting [91]. Together, these results indicate that social stimuli can serve as cues that prompt and perpetuate drug-seeking and use.

\section{Drug Interoceptive Stimuli and Learning Processes Related to Substance Use Disorders}

\section{Animal Models}

Consider the interoceptive stimuli (i.e., internal drug states) associated with drinking alcohol in which people report feeling "buzzed," "high," or "relaxed." These drug interoceptive stimuli may co-occur with reinforcing events, such as drinking with friends, being in a social setting, or drinking while taking other drugs. Associations formed between drug interoceptive stimuli and these reinforcing events may contribute to ongoing drug use and relapse [92, 93]. Namely, drug interoceptive stimuli can function as cues for drug-seeking and drug-taking [93]. They can also serve as discriminative cues for behavioral responses that may perpetuate drug use [94, 95].

Supporting the latter idea, animal models such as the "discriminated goal-tracking task" show that drug interoceptive stimuli can readily guide reward-seeking behavior [22, 96-99]. In these studies, the experimenter administers either a drug (e.g., nicotine) or vehicle (e.g., saline) prior to daily conditioning sessions. During conditioning sessions, sucrose is intermittently presented into a fluid receptacle for oral intake only in the drug sessions. As such, with training, the drug interoceptive stimuli come to control anticipatory rewardseeking (goal-tracking) behavior. This effect is evidenced by increased entries into the fluid receptacle in drug sessions, relative to vehicle sessions. Importantly, rats also learn to withhold reward-seeking behavior in nonreinforced, vehicle sessions. If the experimental parameters are arranged in such a manner that sucrose delivery only occurs on vehicle sessions, then the opposite association can also be trained, such that rats learn to make receptacle entries on vehicle sessions and withhold receptacle entries on drug sessions [22]. Furthermore, rats previously conditioned to an interoceptive stimulus that undergo extinction sessions in which there are nonreinforced presentations of the drug interoceptive stimuli show decreases in reward-seeking behavior [97-100]. As such, understanding these learning processes may be important to consider for behavioral interventions to maintain drug abstinence.

In addition to serving as discriminative stimuli, drug interoceptive stimuli can also function as occasion setters [101-106], a property of drug-associated contexts that is thought to be important for renewal. In this case, the drug interoceptive stimuli set the occasion for when the offset of a light cue will be followed by sucrose. For example, Randall and colleagues [104, 107] used such a procedure to determine whether the interoceptive stimuli of two co-abused substances (alcohol and nicotine) experienced together differed in some qualitative fashion from the interoceptive effects of either drug alone. Rats were administered a nicotine+alcohol cocktail or water by an experimenter prior to daily training sessions. On sessions in which rats were treated with nicotine+alcohol, light offset was followed by sucrose presentation. On sessions in which rats were treated with vehicle (i.e., water), light offset was not followed by sucrose presentation. In separate experiments, the inverse was conditioned, such that light offset was followed by sucrose in vehicle, but not nicotine+alcohol sessions. In these experiments, interoceptive drug stimuli could be conditioned to specific training conditions. That is, the interoceptive drug state set the occasion for whether or not offset of the stimulus light was followed by sucrose reinforcement. Moreover, these experiments showed that it was the specific dose combination of the drug cocktail that proved to be the most effective occasion setter (i.e., greatest level of goal-tracking behavior) when assessed in a dose-response curve, demonstrating a great deal of strength imbued to the specific training parameters.

\section{Human Studies}

There has been interest in the role of interoception in a variety of psychiatric conditions including anxiety, major depression, and substance use disorder, as individuals with these conditions have been described as having disruptions in interoceptive awareness [108-113]. Specifically, these disruptions are described as a disconnection between an individual's expectations, what they perceive, and the actual interoceptive state. For example, an individual with alcohol use disorder may have a particular expectation of the effects from a single drink, and the mismatch between the expectation and perception of their own interoceptive state may drive increased drinking to achieve the desired interoceptive state. In support of this idea, in a recent neuroimaging study focusing on the relation between insula activity and interoceptive state, individuals with 
stimulant use disorder (cocaine and amphetamine) showed exaggerated perception of heartbeat sensations compared with controls. Interestingly, this effect was associated with decreased dorsal dysgranular insula activation compared with controls [114]. The authors postulated that this data pattern may suggest that with repeated stimulant use the individual's perception of heartbeat changes leads to a suppression of attention of the insula to these sensations, which in turn may result in the individual needing to engage in escalated drugtaking to maintain the desired interoceptive state. Therefore, it is likely important to consider how attention to interoceptive signals may impact cravings and prime relapse, and this idea may be especially relevant to interoceptive signals associated with drug withdrawal.

Interoceptive stimuli associated with drug use can be viewed as an "internal context" and continued drug use can affect interoceptive processing. Within this framework, it is important to consider that this internal context may play a key role when one considers factors that promote continued drug use, relapse, and abstinence. Previous work has found that even immune responses can be conditioned by drug cues, reinforcing the hypothesis that contextual cues have power over behavior and physiology [115]. Moreover, interoceptive states that are related to, but not directly caused by the pharmacological effects of drugs, such as anxiety or malaise for example, are also important to consider as they can maintain ongoing drug use.

\section{Integrating Context into Treatment Development}

\section{Animal Models}

\section{Pharmacology}

Several pharmacological agents that are already approved for use in people (e.g., naltrexone, rimonabant, varenicline, cannabidiol) reduce the ability of drug-associated contexts to promote drug-seeking behavior in animal models, specifically renewal [36, 38, 40, 116-118]. As well, preclinical studies show that dopamine [42, 43, 54, 119-121], glutamate [18, $120,122,123]$, and opioid [36, 118] systems are important in mediating the impact of drug-associated contexts on drugseeking behavior. These and related studies on the neural and psychological processes that regulate the influence of context in substance use disorders $[15,50,124]$ provide a rich vein of data that can be used to inform treatment development.

Given the evidence supporting context as a factor to consider drug use and substance use disorders, future treatmentoriented research would benefit from conducting assessments in context-dependent tasks (e.g., renewal, cue reactivity). As substance use disorders do not discriminate by gender [125,
126], including male and female subjects in preclinical research and gender as a factor in human studies would be essential to ensure a comprehensive evaluation of treatment effectiveness.

\section{Brain Stimulation}

Preclinical studies have found that deep brain stimulation [127] or activation of select neural circuits [128] impacts drug-seeking behavior. Brain stimulation techniques have also been used to study ABA renewal. Specifically, optogenetic activation of neurons in the infralimbic subregion of the medial prefrontal cortex during $\mathrm{CS}$ presentations reduced $\mathrm{ABA}$ renewal of responding to a sucrose-predictive CS [129]. The infralimbic prefrontal cortex is important for the consolidation of extinction learning [130, 131], and activating neurons in this area may suppress renewal by accessing the inhibitory learning acquired during extinction. These results corroborate additional studies showing that activation of the infralimbic prefrontal cortex and its efferent projections to the nucleus accumbens shell reduced drug-seeking in various relapse models $[132,133]$. Modern neuroscience approaches used to understand the causal role of neural circuits in behavior have also revealed that medial prefrontal cortex and anterior insular projections to the nucleus accumbens core are important for mediating drug interoceptive stimulus effects [107]. As well, mesolimbic dopamine inputs from the ventral tegmental areas to the nucleus accumbens shell have been found to be particularly important for the elevation in responding to an alcoholpredictive CS by an alcohol context [60].

These preclinical studies can inform translational research aimed at investigating the use of transcranial magnetic stimulation and transcranial direct current stimulation (tDCS) in the treatment for substance use disorders [134]. tDCS in particular is a burgeoning noninvasive technique that delivers lowintensity electrical current to a targeted brain area through 2 electrodes placed on the scalp. The low-intensity current can change resting membrane potential in the targeted area by hyperpolarizing or depolarizing neurons and, thus, has the capacity of modulating neuronal activity. tDCS has been tested in people with alcohol use disorders, as well as tobacco dependence, with a primary focus on activating the dorsolateral prefrontal cortex. Overall, studies reported significant reductions in craving for alcohol $[135,136]$, cue-evoked craving [137], probability of relapse [138], or both [139]. Similarly, in individuals with tobacco dependence, tDCS reduced cigarette use [140, 141] and cue-evoked craving [137, 142].

These findings suggest that stimulating brain regions involved in inhibitory control (i.e., the prefrontal cortex) can reduce cue-elicited craving for alcohol and cigarettes, which supports the continued exploration of brain stimulation as a method to improve substance use disorder treatment outcomes. Future research using tDCS should be extended to 
examine the effects of this manipulation in context-dependent drug-seeking, cue reactivity, and drug expectancy tasks.

\section{Human Studies}

\section{Mindfulness-Based Relapse Prevention}

Cognitive behavioral therapy is a popular, heterogeneous treatment strategy for substance use disorders that can incorporate different behavioral interventions [143]. Relapse prevention therapy is one type of cognitive behavioral therapy in which treatment-seekers are first taught to identify high-risk triggers for relapse, and then taught cognitive and behavioral skills to promote abstinence. Such skills focus on avoidancebased goals, such as how to avoid high-risk situations and control cravings and negative affect by diverting attention from urges and by finding alternative lifestyle practices to engage in [144]. Although relapse prevention therapy can help people abstain from tobacco and alcohol use [145], high-risk triggers for relapse are pervasive and unpredictable, making complete avoidance unfeasible. Relapse prevention therapy also does not teach treatment-seekers to learn to tolerate and live with the causes of craving and negative affect that can result from being abstinent from drugs [146]. These factors may contribute to relapse remaining an issue even after relapse prevention therapy [145, 147]. Providing treatment-seekers with skills to cope with experiencing (rather than avoiding) high-risk triggers might improve treatment effectiveness.

Mindfulness is a promising treatment option for substance use disorders that uses exposure-based approaches to develop skills for becoming open-minded and accepting of life experiences [148]. This approach allows people in recovery from substance use disorders to become cognizant of stimuli (e.g., interoception, affect, physical sensations, environments) that might contribute to their individual propensity to relapse. Interestingly, mindfulness training has been used in conjunction with relapse prevention therapy (known as mindfulnessbased relapse prevention) to treat substance use disorders [146, 149-153]. In this approach, treatment-seekers are trained to recognize high-risk triggers for relapse; however, rather than avoiding them, treatment-seekers receive cognitive, behavioral, and mindfulness training to help tolerate and cope with the discomfort induced by those triggers. Importantly, treatment-seekers are trained to promote continued abstinence through mindfulness practice if they enter drug-associated contexts [153]. An added benefit of mindfulness-based relapse prevention is that experiencing current thoughts and emotions without avoiding them can serve as a form of exposure therapy, which over time, may facilitate the extinction of conditioned responses that elicit triggering states, such as craving and negative affect [154].

Accordingly, the literature suggests that mindfulness-based relapse prevention produces enduring periods of sobriety. In one study, a sample of nicotine-dependent participants showed a greater reduction in cigarette use and a greater number of individuals remaining abstinent at a 17-week follow-up, compared to a control treatment [146]. Similarly, in a sample of participants with an alcohol use disorder, mindfulnessbased relapse prevention and traditional relapse prevention therapy produced a higher probability of abstinence compared with nontreatment controls at a 6-month follow-up. However, at 12 months, people who had received mindfulness-based relapse prevention treatment had a higher probability of not engaging in heavy drinking compared to traditional relapse prevention therapy [150].

Mindfulness-based relapse prevention could be a highly effective approach for extinguishing the motivational properties of drug-associated contexts in a naturalistic manner. This approach contrasts with cue exposure therapy, which involves systematic exposure to nonreinforced proximal drug cues with a therapist in treatment seeking but nonetheless leaves treatment-seekers susceptible to renewal effects [155-157]. Virtual reality could be used to allow treatment-seekers to practice and establish mindfulness-based relapse prevention skills in simulated drug-associated contexts, which could also facilitate the generalization of those skills to real-world, druguse environments.

\section{Cognitive Behavioral Group Therapy}

Because social setting plays a vital role in drug use, incorporating a social element into treatment interventions might help boost their efficacy. Indeed, preclinical studies have found that voluntary access to a conspecific has protective effects against drug self-administration and craving in both female and male animals $[158,159]$.

Implementing group-based exposure treatments in multiple, drug-related environments could be one approach, and in this regard, cognitive behavioral group therapy is a promising option. For example, in patients with social phobias, traditional cognitive behavioral therapy treatment was intermixed with "behavioral experiments," during which patients worked in groups to learn how to overcome symptoms of social phobia [160-162]. They conducted various group tasks (e.g., doing a conga line down a busy street) and then compared predicted versus actual outcomes (e.g., the cost of attracting attention to themselves). A similar therapy for substance use disorders could be developed in which treatmentseekers could meet as a group and undergo live exposure to proximal drug cues, ideally juxtaposed against relevant drugassociated contexts. Behavioral experiments could be tailored to the group and might include tasks like practicing ordering a nonalcoholic drink at a bar, or refusing the offer of a cigarette. These experiments would serve as rehearsals for future times when treatment-seekers might be in social contexts where they are invited to participate in drug use. They would provide a 
supervised, social context in which treatment-seekers could practice long-lasting coping strategies to facilitate enduring recovery.

It is critical to stress that introducing people who are attempting abstinence to drug contexts can be hazardous. Live exposure to drug-associated contexts creates a high-risk situation for treatment-seekers, making them vulnerable to relapse. Virtual reality could be used to help overcome this caveat, providing the advantages of initially exposing treatment-seekers to a range of drug-associated contexts in a regulated environment where there is reduced risk of engaging in drug use. Subsequent sessions could incrementally extend to real-world drug environments and social stimuli for maximum generalizability to natural scenarios. The unique and invaluable aspect of this cognitive behavioral group therapy is that it can potentially extinguish multiple drug-associated stimuli, including drug-associated contexts, internal states, and social stimuli.

\section{Conclusions}

Drug-associated contexts are an influential factor to contend with in drug use and substance use disorders, and research reviewed herein supports this hypothesis. Parallel findings in preclinical studies and human participants show robust and reliable effects of drug-associated contexts on multiple processes that can accelerate drug use and promote relapse. Based on these results, translational research on pharmacological and neural interventions could be greatly improved by the inclusion of context-based experimental manipulations. As well, treatment practices that equip treatment-seekers with the skills to cope with being in drug-associated contexts and that offer opportunities to practice and establish those skills under safe conditions might ultimately facilitate long-term abstinence. Ultimately, considering drug-associated contexts as a factor in the development and implementation of treatment strategies is likely to improve outcomes for people with substance use disorders.

Acknowledgments Mandy Rita LeCocq was supported by a Faculty of Arts and Science Graduate Fellowship from Concordia University. Patrick A. Randall was supported by AA024674 from the National Institute on Alcohol Abuse and Alcoholism. Joyce Besheer was supported by grants from the National Institutes of Health (AA011605, AA026537, AA024095, AA026996, AA025582). Nadia Chaudhri was supported by grants from the Canadian Institutes of. Health Research (MOP-137030), Fonds de la recherche en santé du Québec (Chercheur Boursier Junior 2), Canada Foundation for Innovation (John R. Evans Leaders Fund), and Natural Sciences and Engineering Research Council of Canada (2017-04802).

Required Author Forms Disclosure forms provided by the authors are available with the online version of this article.

\section{References}

1. Stewart J. Psychological and neural mechanisms of relapse. Philos Trans R Soc B Biol Sci 2008;363:3147-58.

2. Milton AL, Everitt BJ. The persistence of maladaptive memory: addiction, drug memories and anti-relapse treatments. Neurosci Biobehav Rev 2012;36:1119-39.

3. Caggiula AR, Donny EC, White AR, et al. Cue dependency of nicotine self-administration and smoking. Pharmacol Biochem Behav 2001;70:515-30.

4. Ludwig AM. Pavlov's "bells" and alcohol craving. Addict Behav 1986;11(2):87-91.

5. Siegel S. Pavlovian conditioning and drug overdose: when tolerance fails. Addict Res Theory 2001;9:503-13.

6. Siegel, S, Hinson RE, Krank MD, McCully JM. Heroin "overdose" death: contribution of drug-associated environmental cues. Science. 1982;216:436-7.

7. Siegel S, Hinson RE, Krank MD. The role of predrug signals in morphine analgesic tolerance: support for a Pavlovian conditioning model of tolerance. J Exp Psychol Anim Behav Process 1978;4:188-96.

8. Spyraki C, Fibiger HC, Phillips AG. Dopaminergic substrates of amphetamine-induced place preference conditioning. Brain Res 1982;253:185-93.

9. Stewart RB, Murphy JM, McBride WJ, Lumeng L, Li TK. Place conditioning with alcohol in alcohol-preferring and -nonpreferring rats. Pharmacol Biochem Behav 1996;53:487-91.

10. Cunningham CL, Noble D. Methamphetamine-induced conditioned place preference or aversion depending on dose and presence of drug. Ann N Y Acad Sci 1992;654:431-3.

11. Siegel S. Drug tolerance, drug addiction, and drug anticipation. Curr Dir Psychol Sci 2005;14:296-300.

12. McCusker CG, Brown K. Alcohol-predictive cues enhance tolerance to and precipitate "craving" for alcohol in social drinkers. J Stud Alcohol 1990;51:494-9.

13. Bouton ME. A learning theory perspective on lapse, relapse, and the maintenance of behavior change. Health Psychol 2000;19:5763.

14. Conklin CA, Tiffany ST. Applying extinction research and theory to cue-exposure addiction treatments. Addiction. 2002;97:15567.

15. Crombag HS, Bossert JM, Koya E, Shaham Y. Context-induced relapse to drug seeking: a review. Philos Trans R Soc B Biol Sci 2008;363:3233-43.

16. Conklin CA. Environments as cues to smoke: implications for human extinction-based research and treatment. Exp Clin Psychopharmacol 2006;14:12-9.

17. Conklin CA, Robin N, Perkins KA, Salkeld RP, McClernon FJ Proximal versus distal cues to smoke: the effects of environments on smokers' cue-reactivity. Exp Clin Psychopharmacol 2008;16: 207-14.

18. Sciascia JM, Reese RM, Janak PH, Chaudhri N. Alcohol-seeking triggered by discrete Pavlovian cues is invigorated by alcohol contexts and mediated by glutamate signaling in the basolateral amygdala. Neuropsychopharmacology. 2015;40:2801-12.

19. Dimet AL, Cisneros IE, Fox RG, et al. A protocol for measuring cue reactivity in a rat model of cocaine use disorder. J Vis Exp 2018;136:e55864.

20. Kruzich PJ, Congleton KM, See RE. Conditioned reinstatement of drug-seeking behavior with a discrete compound stimulus classically conditioned with intravenous cocaine. Behav Neurosci 2001;115:1086-92.

21. Valyear MD, Villaruel FR, Chaudhri N. Alcohol-seeking and relapse: a focus on incentive salience and contextual conditioning. Behav Process 2017;141:26-32. 
22. Besheer J, Palmatier MI, Metschke DM, Bevins RA. Nicotine as a signal for the presence or absence of sucrose reward: a Pavlovian drug appetitive conditioning preparation in rats. Psychopharmacology 2004;172:108-17.

23. Schepers ST, Bouton ME. Hunger as a context: food seeking that is inhibited during hunger can renew in the context of satiety. Psychol Sci 2017;28:1640-8.

24. Peacock A, Leung J, Larney S, et al. Global statistics on alcohol, tobacco and illicit drug use: 2017 status report. Addiction. 2018;113:1905-26.

25. Miller WR, Wilbourne PL. Mesa Grande: a methodological analysis of clinical trials of treatments for alcohol use disorders. Addiction. 2002;97:265-77.

26. Ziedonis D, Das S, Larkin C. Tobacco use disorder and treatment: new challenges and opportunities. Dialogues Clin Neurosci 2017;19:271-80.

27. Kranzler HR, Soyka M. Diagnosis and pharmacotherapy of alcohol use disorder a review. JAMA - J Am Med Assoc 2018;320: 815-24.

28. Bouton ME, Bolles RC. Contextual control of the extinction of conditioned fear. Learn Motiv 1979;10:445-66.

29. Crombag HS, Shaham Y. Renewal of drug seeking by contextual cues after prolonged extinction in rats. Behav Neurosci 2002;116: 169-73.

30. Bossert JM, Liu SY, Lu L, Shaham Y. A role of ventral tegmental area glutamate in contextual cue-induced relapse to heroin seeking. J Neurosci 2004;24:10726-30.

31. Bossert JM, Gray SM, Lu L, Shaham Y. Activation of group II metabotropic glutamate receptors in the nucleus accumbens shell attenuates context-induced relapse to heroin seeking. Neuropsychopharmacology. 2006;31:2197-209.

32. Xie X, Ramirez DR, Lasseter HC, Fuchs RA. Effects of mGluR1 antagonism in the dorsal hippocampus on drug context-induced reinstatement of cocaine-seeking behavior in rats. Psychopharmacology. 2009;208:1.

33. Pelloux Y, Minier-Toribio A, Hoots JK, Bossert JM, Shaham Y. Opposite effects of basolateral amygdala inactivation on contextinduced relapse to cocaine seeking after extinction versus punishment. J Neurosci 2018;38:51-9.

34. Hamlin AS, Clemens KJ, McNally GP. Renewal of extinguished cocaine-seeking. Neuroscience. 2008;151:659-70.

35. Fuchs RA, Evans KA, Ledford CC, et al. The role of the dorsomedial prefrontal cortex, basolateral amygdala, and dorsal hippocampus in contextual reinstatement of cocaine seeking in rats. Neuropsychopharmacology. 2005;30:296-309.

36. Bossert JM, Hoots JK, Fredriksson I, et al. Role of mu, but not delta or kappa, opioid receptors in context-induced reinstatement of oxycodone seeking. Eur J Neurosci 2019;50:2075-85.

37. Wing VC, Shoaib M. Contextual stimuli modulate extinction and reinstatement in rodents self-administering intravenous nicotine. Psychopharmacology 2008;200:357-65.

38. Diergaarde L, de Vries W, Raasø H, Schoffelmeer ANM, De Vries TJ. Contextual renewal of nicotine seeking in rats and its suppression by the cannabinoid-1 receptor antagonist Rimonabant (SR141716A). Neuropharmacology. 2008;55:712-6.

39. Sabioni P, Di Ciano P, Le Foll B. Effect of a D3 receptor antagonist on context-induced reinstatement of nicotine seeking. Prog NeuroPsychopharmacology Biol Psychiatry 2016;64:149-54.

40. Burattini C, Gill TM, Aicardi G, Janak PH. The ethanol selfadministration context as a reinstatement cue: acute effects of naltrexone. Neuroscience. 2006;139:877-87.

41. Zironi I, Burattini C, Aicardi G, Janak PH. Context is a trigger for relapse to alcohol. Behav Brain Res 2006;167:150-5.

42. Tsiang MT, Janak PH. Alcohol seeking in C57BL/6 mice induced by conditioned cues and contexts in the extinction-reinstatement model. Alcohol. 2006;38:81-8.
43. Hamlin AS, Newby J, McNally GP. The neural correlates and role of D1 dopamine receptors in renewal of extinguished alcoholseeking. Neuroscience. 2007;146:525-36.

44. Chaudhri N, Sahuque LL, Janak PH. Ethanol seeking triggered by environmental context is attenuated by blocking dopamine D1 receptors in the nucleus accumbens core and shell in rats. Psychopharmacology. 2009;207:303-314.

45. Hamlin AS, Blatchford KE, McNally GP. Renewal of an extinguished instrumental response: neural correlates and the role of D1 dopamine receptors. Neuroscience. 2006;143:25-38.

46. Schepers ST, Bouton ME. Stress as a context: stress causes relapse of inhibited food seeking if it has been associated with prior food seeking. Appetite. 2019;132:131-8.

47. Bouton ME, Todd TP, Vurbic D, Winterbauer NE. Renewal after the extinction of free operant behavior. Learn Behav 2011;39:5767.

48. Todd TP, Winterbauer NE, Bouton ME. Contextual control of appetite. Renewal of inhibited food-seeking behavior in sated rats after extinction. Appetite. 2012;58:484-9.

49. Chaudhri N, Sahuque LL, Cone JJ, Janak PH. Reinstated ethanolseeking in rats is modulated by environmental context and requires the nucleus accumbens core. Eur J Neurosci 2008;28:2288-98.

50. Marchant NJ, Campbell EJ, Pelloux Y, Bossert JM, Shaham Y. Context-induced relapse after extinction versus punishment: similarities and differences. Psychopharmacology. 2019;236:439448.

51. Marchant NJ, Khuc TN, Pickens CL, Bonci A, Shaham Y. Context-induced relapse to alcohol seeking after punishment in a rat model. Biol Psychiatry 2013;73:256-62.

52. Tabbara RI, Maddux JMN, Beharry PF, Iannuzzi J, Chaudhri N. Effects of sucrose concentration and water deprivation on pavlovian conditioning and responding for conditioned reinforcement. Behav Neurosci 2016;130:231-42.

53. Anderson LC, Petrovich GD. Renewal of conditioned responding to food cues in rats: sex differences and relevance of estradiol. Physiol Behav 2015;151:338-44.

54. Sciascia JM, Mendoza J, Chaudhri N. Blocking dopamine D1-like receptors attenuates context-induced renewal of Pavlovianconditioned alcohol-seeking in rats. Alcohol Clin Exp Res 2014;38:418-27.

55. Marinelli PW, Funk D, Harding S, Li Z, Juzytsch W, Lê AD. Roles of opioid receptor subtypes in mediating alcohol-seeking induced by discrete cues and context. Eur J Neurosci 2009;30:671-9.

56. Bouton ME, Ricker ST. Renewal of extinguished responding in a second context. Anim Learn Behav 1994;22:317-24.

57. Thewissen R, Snijders SJBD, Havermans RC, van den Hout M, Jansen A. Renewal of cue-elicited urge to smoke: implications for cue exposure treatment. Behav Res Ther 2006;44:1441-9.

58. Collins BN, Brandon TH. Effects of extinction context and retrieval cues on alcohol cue reactivity among nonalcoholic drinkers. J Consult Clin Psychol 2002;70:390-7.

59. Millan EZ, Reese RM, Grossman CD, Chaudhri N, Janak PH. Nucleus accumbens and posterior amygdala mediate cuetriggered alcohol seeking and suppress behavior during the omission of alcohol-predictive cues. Neuropsychopharmacology. 2015;40:2555-65.

60. Valyear MD, Glovaci I, Zaari A, et al. Divergent mesolimbic dopamine circuits support alcohol-seeking triggered by discrete cues and contexts. bioRxiv. 2018 1;475343.

61. Remedios J, Woods C, Tardif C, Janak PH, Chaudhri N. Pavlovian-conditioned alcohol-seeking behavior in rats is invigorated by the interaction between discrete and contextual alcohol cues: implications for relapse. Brain Behav 2014;4:278-89.

62. Epstein DH, Tyburski M, Craig IM, et al. Real-time tracking of neighborhood surroundings and mood in urban drug misusers: 
application of a new method to study behavior in its geographical context. Drug Alcohol Depend 2014;134:22-9.

63. Luczak SE, Rosen IG, Wall TL. Development of a real-time repeated-measures assessment protocol to capture change over the course of a drinking episode. Alcohol Alcohol 2015;50:180-7.

64. Muraven M, Collins RL, Morsheimer ET, Shiffman S, Paty JA. One too many: predicting future alcohol consumption following heavy drinking. Exp Clin Psychopharmacol 2005;13:127-36.

65. Simons JS, Gaher RM, Oliver MNI, Bush JA, Palmer MA. An experience sampling study of associations between affect and alcohol use and problems among college students. J Stud Alcohol 2005;66:459-69.

66. Shapiro D, Jamner LD, Davydov DM, James P. Situations and moods associated with smoking in everyday life. Psychol Addict Behav 2002; 16:342-5.

67. Shiffman S, Gwaltney CJ, Balabanis MH, et al. Immediate antecedents of cigarette smoking: an analysis from ecological momentary assessment. J Abnorm Psychol 2002;111:531-45.

68. Shiffman S, Paty J. Smoking patterns and dependence: contrasting chippers and heavy smokers. J Abnorm Psychol 2006;115:50923.

69. Conklin CA, Perkins KA, Robin N, McClernon FJ, Salkeld RP. Bringing the real world into the laboratory: personal smoking and nonsmoking environments. Drug Alcohol Depend 2010;111:58 63.

70. Conklin CA, McClernon FJ, Vella EJ, et al. Combined smoking cues enhance reactivity and predict immediate subsequent smoking. Nicotine Tob Res 2019;21:241-8.

71. Stevenson JG, Oliver JA, Hallyburton MB, Sweitzer MM, Conklin CA, McClernon FJ. Smoking environment cues reduce ability to resist smoking as measured by a delay to smoking task. Addict Behav 2017;67:49-52.

72. Lau-Barraco C, Dunn ME. Environmental context effects on alcohol cognitions and immediate alcohol consumption. Addict Res Theory 2009;17:306-14.

73. Blaine SK, Nautiyal N, Hart R, Guarnaccia JB, Sinha R. Craving, cortisol and behavioral alcohol motivation responses to stress and alcohol cue contexts and discrete cues in binge and non-binge drinkers. Addict Biol 2018;24:1096-108.

74. Brown SA, Goldman MS, Inn A, Anderson LR. Expectations of reinforcement from alcohol: their domain and relation to drinking patterns. J Consult Clin Psychol 1980;48:419-26.

75. Brown SA, Goldman MS, Christiansen BA. Do alcohol expectancies mediate drinking patterns of adults? J Consult Clin Psychol 1985;53:512-9.

76. Wall AM, McKee SA, Hinson RE. Assessing variation in alcohol outcome expectancies across environmental context: an examination of the situational-specificity hypothesis. Psychol Addict Behav 2000;14:367-75.

77. Wall AM, McKee SA, Hinson RE, Goldstein A. Examining alcohol outcome expectancies in laboratory and naturalistic bar settings: a within-subject experimental analysis. Psychol Addict Behav 2001;15:219-26.

78. Monk RL, Heim D. Environmental context effects on alcoholrelated outcome expectancies, efficacy, and norms: a field study. Psychol Addict Behav 2013;27:814-8.

79. Conklin CA, Salkeld RP, Perkins KA, Robin N. Do people serve as cues to smoke? Nicotine Tob Res 2013;15:2081-7.

80. Lochbuehler K, Peters M, Scholte RHJ, Engels RCME. Effects of smoking cues in movies on immediate smoking behavior. Nicotine Tob Res 2010;12:913-8.

81. Shmueli D, Prochaska JJ, Glantz SA. Effect of smoking scenes in films on immediate smoking. A randomized controlled study. Am J Prev Med 2010;38:351-8.
82. Glad W, Adesso VJ. The relative importance of socially induced tension and behavioral contagion for smoking behavior. J Abnorm Psychol 1976;85:119-21.

83. Harakeh Z, Engels RCME, Van Baaren RB, Scholte RHJ. Imitation of cigarette smoking: an experimental study on smoking in a naturalistic setting. Drug Alcohol Depend 2007;86:199-206.

84. Harakeh Z, Vollebergh WAM. The impact of active and passive peer influence on young adult smoking: an experimental study. Drug Alcohol Depend 2012;121:220-3.

85. Harakeh Z, Vollebergh WAM. Actions speak louder than words: an experiment on the impact of peers discouraging young adult smoking. Eur Addict Res 2011;17:316-20.

86. Doty $\mathrm{P}$, de Wit $\mathrm{H}$. Effect of setting on the reinforcing and subjective effects of ethanol in social drinkers. Psychopharmacology 1995;118:19-27.

87. Tomaszewski RJ, Strickler DP, Maxwell WA. Influence of social setting and social drinking stimuli on drinking behavior. Addict Behav 1980;5:235-40.

88. Dallas R, Field M, Jones A, Christiansen P, Rose A, Robinson E. Influenced but unaware: social influence on alcohol drinking among social acquaintances. Alcohol Clin Exp Res 2014;38: 1448-53.

89. Monk RL, Qureshi AW, McNeill A, Erskine-Shaw M, Heim D. Perfect for a gin and tonic: how context drives consumption within a modified bogus taste test. Alcohol Alcohol 2018;53:228-34.

90. Kirkpatrick MG, De Wit H. In the company of others: social factors alter acute alcohol effects. Psychopharmacology 2013;230:215-26.

91. Abrams D, Hopthrow T, Hulbert L, Frings D. "Groupdrink"? The effect of alcohol on risk attraction among groups versus individuals. J Stud Alcohol 2006;67:628-36.

92. Bevins RA, Palmatier MI. Extending the role of associative learning processes in nicotine addiction. Behav Cogn Neurosci Rev 2004;3:143-58.

93. Bevins RA, Besheer J. Interoception and learning: import to understanding and treating diseases and psychopathologies. ACS Chem Neurosci 2014;5:624-31.

94. Perkins KA. Discriminative stimulus effects of nicotine in humans. Handb Exp Pharmacol 2009;192:369-400.

95. Bolin BL, Alcorn JL, Reynolds AR, Lile JA, Stoops WW, Rush CR. Human drug discrimination: elucidating the neuropharmacology of commonly abused illicit drugs. In: Porter JH, Prus AJ, editors. The behavioral neuroscience of drug discrimination. Cham: Springer International Publishing; 2018. p. 261-95.

96. Randall PA, Fortino B, Huynh YW, et al. Effects of nicotine conditioning history on alcohol and methamphetamine selfadministration in rats. Pharmacol Biochem Behav 2019;179:1-8.

97. Pittenger ST, Zeplin LC, Dwoskin LP, Bevins RA. The effect of switching pharmacological intervention during extinction on nicotine-evoked conditioned responding in rats. Psychopharmacology. 2015;232:4347-4358.

98. Thompson BM, Barrett ST, Bevins RA. Exploring the interoceptive stimulus effects of nicotine and varenicline. Pharmacol Biochem Behav 2019;181:9-16.

99. Charntikov S, Dewit NR, Bevins RA. Interoceptive conditioning with nicotine using extinction and re-extinction to assess stimulus similarity with bupropion. Neuropharmacology. 2014;86:181-91.

100. Polewan RJ, Savala SA, Bevins RA. Interoceptive conditioning with the nicotine stimulus: extinction learning as a method for assessing stimulus similarity across doses. Behav Pharmacol 2013;24:45-54.

101. Palmatier MI, Bevins RA. Occasion setting by drug states: functional equivalence following similar training history. Behav Brain Res 2008; 195:260-70.

102. Murray JE, Walker AW, Li C, Wells NR, Penrod RD, Bevins RA. Nicotine trained as a negative feature passes the retardation-of- 
acquisition and summation tests of a conditioned inhibitor. Learn Mem 2011;18:452-8.

103. Dion AM, Reichel CM, Bevins RA. Sign- vs. goal-tracking in a feature positive discrimination task with nicotine: importance of spatial location of the conditional stimulus. Behav Brain Res. 2011;218:341-345.

104. Randall PA, Cannady R, Besheer J. The nicotine + alcohol interoceptive drug state: contribution of the components and effects of varenicline in rats. Psychopharmacology 2016;233:3061-74.

105. Jaramillo AA, Agan VE, Makhijani VH, Pedroza S, McElligott ZA, Besheer J. Functional role for suppression of the insularstriatal circuit in modulating interoceptive effects of alcohol. Addict Biol 2018;23:1020-31.

106. Besheer J, Fisher KR, Durant B. Assessment of the interoceptive effects of alcohol in rats using short-term training procedures. Alcohol. 2012;46:747-55.

107. Randall PA, McElligott ZA, Besheer J. Role of mPFC and nucleus accumbens circuitry in modulation of a nicotine plus alcohol compound drug state. Addict Biol. 2019; e12782.

108. Farb N, Daubenmier J, Price CJ, et al. Interoception, contemplative practice, and health. Front Psychol 2015;6:1-26.

109. Harshaw C. Interoceptive dysfunction: toward an integrated framework for understanding somatic and affective disturbance in depression. Psychol Bull 2015;141:311-63.

110. Goodkind M, Eickhoff SB, Oathes DJ, et al. Identification of a common neurobiological substrate for mental Illness. JAMA Psychiatry 2015;72:305-15.

111. Barrett LF, Simmons WK. Interoceptive predictions in the brain. Nat Rev Neurosci 2015;16:419-29.

112. Naqvi NH, Bechara A. The insula and drug addiction: an interoceptive view of pleasure, urges, and decision-making. Brain Struct Funct 2010;214:435-50.

113. Paulus MP, Stewart JL. Interoception and drug addiction. Neuropharmacology. 2014;76:342-50.

114. Stewart JL, Khalsa SS, Kuplicki R, Puhl M, T1000 Investigators, Paulus MP. Interoceptive attention in opioid and stimulant use disorder. Addict Biol. 2019; e12831.

115. Szczytkowski JL, Lebonville C, Hutson L, Fuchs RA, Lysle DT. Heroin-induced conditioned immunomodulation requires expression of IL-1 $\beta$ in the dorsal hippocampus. Brain Behav Immun 2013;30:95-102.

116. Lacroix F, Pettorelli A, Maddux JMN, Heidari-Jam A, Chaudhri $\mathrm{N}$. Varenicline reduces context-induced relapse to alcohol-seeking through actions in the nucleus accumbens. Neuropsychopharmacology. 2017;42:1037-48.

117. Weiss F, Gonzalez-Cuevas G. Unique treatment potential of cannabidiol for the prevention of relapse to drug use. Neuropsychopharmacology. 2019;44:229.

118. Marinelli PW, Funk D, Juzytsch W, Li Z, Lê AD. Effects of opioid receptor blockade on the renewal of alcohol seeking induced by context: relationship to c-fos mRNA expression. Eur J Neurosci 2007;26:2815-23.

119. Crombag HS, Grimm JW, Shaham Y. Effect of dopamine receptor antagonists on renewal of cocaine seeking by reexposure to drugassociated contextual cues. Neuropsychopharmacology. 2002;27: $1006-15$.

120. Bossert JM, Poles GC, Wihbey KA, Koya E, Shaham Y. Differential effects of blockade of dopamine D1-family receptors in nucleus accumbens core or shell on reinstatement of heroin seeking induced by contextual and discrete cues. J Neurosci 2007:27:12655-63.

121. Liu X, Weiss F. Reversal of ethanol-seeking behavior by D1 and D2 antagonists in an animal model of relapse: differences in antagonist potency in previously ethanol-dependent versus nondependent rats. J Pharmacol Exp Ther 2002;300:882-9.
122. Khoo SY-S, LeCocq MR, Deyab GE, Chaudhri N. Context and topography determine the role of basolateral amygdala metabotropic glutamate receptor 5 in appetitive Pavlovian responding. Neuropsychopharmacology. 2019;44:1524-33.

123. Knackstedt LA, Schwendt M. MGlu5 receptors and relapse to cocaine-seeking: the role of receptor trafficking in postrelapse extinction learning deficits. Neural Plast. 2016;10 pages.

124. Zachary Rosenthal M, Kutlu MG. Translation of associative learning models into extinction reminders delivered via mobile phones during cue exposure interventions for substance use. Psychol Addict Behav 2014;28:863-71.

125. Pool N, Dell CA. Girls, women and substance use. Ottawa, ON, Canada; 2005.

126. Anthony JC, Warner LA, Kessler RC. Comparative epidemiology of dependence on tobacco, alcohol, controlled substances, and inhalants: basic findings from the National Comorbidity Survey. Exp Clin Psychopharmacol 1994;2(3):244-68.

127. Vassoler FM, Schmidt HD, Gerard ME, et al. Deep brain stimulation of the nucleus accumbens shell attenuates cocaine priminginduced reinstatement of drug seeking in rats. J Neurosci 2008;28: 8735-9.

128. Chen BT, Yau HJ, Hatch C, et al. Rescuing cocaine-induced prefrontal cortex hypoactivity prevents compulsive cocaine seeking. Nature. 2013;496:359-62.

129. Villaruel FR, Lacroix F, Sanio C, Sparks DW, Chapman CA, Chaudhri N. Optogenetic activation of the infralimbic cortex suppresses the return of appetitive Pavlovian-conditioned responding following extinction. Cereb Cortex 2018;28:4210-21.

130. Laurent V, Westbrook RF. Inactivation of the infralimbic but not the prelimbic cortex impairs consolidation and retrieval of fear extinction. Learn Mem 2009;16:520-9.

131. Lalumiere RT, Niehoff KE, Kalivas PW. The infralimbic cortex regulates the consolidation of extinction after cocaine self-administration. Learn Mem 2010;17:168-75.

132. Chen W, Wang Y, Sun A, et al. Activation of AMPA receptor in the infralimbic cortex facilitates extinction and attenuates the heroin-seeking behavior in rats. Neurosci Lett 2016;612:126-31.

133. Peters J, LaLumiere RT, Kalivas PW. Infralimbic prefrontal cortex is responsible for inhibiting cocaine seeking in extinguished rats. J Neurosci 2008;28:6046-53.

134. Terraneo A, Leggio L, Saladini M, Ermani M, Bonci A, Gallimberti L. Transcranial magnetic stimulation of dorsolateral prefrontal cortex reduces cocaine use: a pilot study. Eur Neuropsychopharmacol 2016;26:37-44.

135. Den Uyl TE, Gladwin TE, Wiers RW. Transcranial direct current stimulation, implicit alcohol associations and craving. Biol Psychol 2015;105:37-42.

136. da Silva MC, Conti CL, Klauss J, Alves LG, do Nascimento Cavalcante HM, Fregni F, et al. Behavioral effects of transcranial direct current stimulation (tDCS) induced dorsolateral prefrontal cortex plasticity in alcohol dependence. J Physiol Paris. 2013;107: 493-502.

137. Boggio PS, Sultani N, Fecteau S, et al. Prefrontal cortex modulation using transcranial DC stimulation reduces alcohol craving: a double-blind, sham-controlled study. Drug Alcohol Depend 2008;92:55-60.

138. Klauss J, Penido Pinheiro LC, Silva Merlo BL, et al. A randomized controlled trial of targeted prefrontal cortex modulation with tDCS in patients with alcohol dependence. Int J Neuropsychopharmacol 2014;17:1793-803.

139. Klauss J, Anders QS, Felippe L V., Nitsche MA, NakamuraPalacios EM. Multiple sessions of transcranial direct current stimulation (tDCS) reduced craving and relapses for alcohol use: a randomized placebo-controlled trial in alcohol use disorder. Front Pharmacol 2018;9:1-11. 
140. Boggio PS, Liguori P, Sultani N, Rezende L, Fecteau S, Fregni F. Cumulative priming effects of cortical stimulation on smoking cue-induced craving. Neurosci Lett 2009;463:82-6.

141. Falcone M, Bernardo L, Ashare RL, et al. Transcranial direct current brain stimulation increases ability to resist smoking. Brain Stimul 2016;9:191-6.

142. Fregni F, Liguori P, Fecteau S, et al. Cortical stimulation of the prefrontal cortex with transcranial direct current stimulation reduces cue-provoked smoking craving: a randomized, shamcontrolled study. J Clin Psychiatry 2008;69:32-40.

143. McHugh RK, Hearon BA, Otto MW. Cognitive behavioral therapy for substance use disorders. Psychiatr Clin 2010;33:511-25.

144. Chung T, Langenbucher J, Labouvie E, Pandina RJ, Moos RH. Changes in alcoholic patients' coping responses predict 12-month treatment outcomes. J Consult Clin Psychol 2001;69:92-100.

145. Irvin JE, Bowers CA, Dunn ME, Wang MC. Efficacy of relapse prevention: a meta-analytic review. J Consult Clin Psychol 1999;67:563-70.

146. Brewer JA, Mallik S, Babuscio TA, et al. Mindfulness training for smoking cessation: results from a randomized controlled trial. Drug Alcohol Depend 2011;119:72-80.

147. Law M, Tang JL. An analysis of the effectiveness of interventions intended to help people stop smoking. JAMA Intern Med 1995;155:1933-41.

148. Bishop SR. Mindfulness: a proposed operational definition. Clin Psychol Sci Pract 2004;11:230-41.

149. Bowen S, Chawla N, Collins SE, et al. Mindfulness-based relapse prevention for substance use disorders: a pilot efficacy trial. Subst Abus 2009;30:295-305.

150. Zgierska A, Rabago D, Zuelsdorff M, Miller M, Coe C, Fleming M. Mindfulness meditation for relapse prevention in alcohol dependence: a feasibility pilot study. J Addict Med 2008;2:165-73.

151. Brewer JA, Sinha R, Chen JA, et al. Mindfulness training and stress reactivity in substance abuse: results from a randomized, controlled stage I pilot study. Subst Abus 2009;30:306-17.
152. Witkiewitz K, Bowen S. Depression, craving, and substance use following a randomized trial of mindfulness-based relapse prevention. J Consult Clin Psychol 2010;78:362-74.

153. Witkiewitz K, Marlatt GA, Walker D. Mindfulness-based relapse prevention for alcohol and substance use disorders. J Cogn Psychother 2005;19:211-28.

154. Baer RA. Mindfulness training as a clinical intervention: a conceptual and empirical review. Clin Psychol Sci Pract 2003;10: 125-43.

155. Drummond DC, Glautier S. A controlled trial of cue exposure treatment in alcohol dependence. J Consult Clin Psychol 1994;62:809-17.

156. Monti PM, Rohsenow DJ, Rubonis A V, et al. Cue exposure with coping skills treatment for male alcoholics: a preliminary investigation. J Consult Clin Psychol 1993;61:1011-9.

157. Raw M, Russell MAH. Rapid smoking, cue-exposure, and support in the modification of smoking. Behav Res Ther 1980;18:363-72.

158. Venniro M, Zhang M, Caprioli D, et al. Volitional social interaction prevents drug addiction in rat models. Nat Neurosci 2018;21: $1520-9$.

159. Venniro M, Russell TI, Zhang M, Shaham Y. Operant social reward decreases incubation of heroin craving in male and female rats. Biol Psychiatry 2019;18-20.

160. McEvoy PM. Effectiveness of cognitive behavioural group therapy for social phobia in a community clinic: a benchmarking study. Behav Res Ther 2007;45:3030-40.

161. Tillfors M, Carlbring P, Furmark T, et al. Treating university students with social phobia and public speaking fears: internet delivered self-help with or without live group exposure sessions. Depress Anxiety 2008;25:708-17.

162. Heimberg RG, Liebowitz MR, Hope DA, et al. Cognitive behavioral group therapy vs phenelzine therapy for social phobia 12week outcome. Arch Gen Psychiatry 1998;55:1133-41.

Publisher's Note Springer Nature remains neutral with regard to jurisdictional claims in published maps and institutional affiliations. 